\title{
Performance of MM-Waves Signals Transportation Technique for Radio over Fiber over System on Fiber Dispersive Links
}

\author{
Tanu Sharma \\ Dept. ECE \\ KIET Group of Institution \\ Ghaziabad (U.P.), India
}

\author{
Parvin Kumar \\ Dept. ECE \\ KIET Group of Institution \\ Ghaziabad (U.P.), India
}

\author{
Pratibha Tanwar \\ Dept. ECE \\ KIET Group of Institution \\ Ghaziabad (U.P.), India
}

\begin{abstract}
This time domain analytical analysis of Radio over Fiber (RoF) system is derived regarding the performance evaluation of external modulation schemes such as optical single side band (OSSB), optical double side band (ODSB) and optical vestigial side band (OVSB) based on mach-zehender modulator (MZM) and phase modulator (PM). It is found that performance related signal to noise ratio is deeply related to the bandwidth of receiver filter and the influence of phase noise is more dominated from a radio frequency signal oscillator rather than the form a laser source in a small differential delay environment. Further, commercial available, economic laser with OVSB scheme help the telecom industry to reduce the designing cost of RoF system.
\end{abstract}

\section{Keywords}

Optical single side band (OSSB), Optical double side band (ODSB), optical vestigial side band (OVSB), MZM configuration, radio over fiber.

\section{INTRODUCTION}

The level of data traffic ever increasing due to demands of subscriber for voice, data and multimedia service that involve the access network to support the high data rates at any time and any where economically. For satisfied the demands, wideband communication system are necessary in both wired system and wireless system [1]. RoF system is a capable for the next generation wireless network as it has capability to achieve multi-gigabit per second data rate to support bandwidth incentives applications. Optical signal sideband modulation has become an attractive technology for achieving long distance RoF system based on transmission highly precise optical sensing. Highly optical resolution optical vector network analysis, Optical wave length conversion, and optical coherence tomography. The OSSB scheme is not affected by the errors induced by the fiber chromatic dispersion, which is serves in the conventional optical double sideband modulated RoF transmission system. Optical single sideband modulation scheme can be implemented various schemes. Majority two schemes such as preferred optical filter and $90^{\circ}$ phase shift procedure [2]. There are two technique generate the optically modulated RF signal: direct and external modulation scheme. Direct modulation scheme suffer from the laser frequency chirp effect and results severe degradation of the system performance. However it can eliminate by using the external modulation scheme. The external modulation scheme is employed the conventional optical double sideband scheme can degrade the received RF signal power due to fiber chromatic dispersion significantly. The overcome the power degradation, an OSSB scheme generated by using a phase shifter and a mach- zehender modulator is employed [3]. OVSB scheme using concatenated MZM and PM configuration. In this scheme by tuning appropriately parameter of the modulator, an equal sideband intensity based scheme generated. It can generate the different sideband modulation schemes. In this paper, investigate the SNR penalty due to the phase noise from a laser and an RF oscillator using the external modulation schemes. For the SNR penalty, the autocorrelation function and PSD function of a received photocurrent are evaluated. The bandwidth of an electrical filter is dealt in the SNR penalty. Since phase noise result increase of required bandwidth and the increased the bandwidth causes an additional SNR penalty. It shows that the phase noise from the RF oscillator, rather than from laser, is relatively the dominant parameter in the short optical distance [1].

RoF system in which data are mixed with RF oscillator and optically modulated by MZM and PM. this signal is then reach to the photo detector $(\mathrm{PD})$ through a single mode fiber. The input signals $x_{0}(\mathrm{t})$ and $x_{1}(t)$ can be expressed as: $x_{0}(\mathrm{t})=\mathrm{A} \operatorname{expj}\left(\omega_{0} \mathrm{t}+\emptyset_{0}(\mathrm{t})\right)$

$x_{1}(\mathrm{t})=\mathrm{V}_{1} \cos \left(\omega_{1} \mathrm{t}+\emptyset_{1}(\mathrm{t})\right)$

Where, $x_{0}(\mathrm{t})$ is the optical signal from a laser, $x_{1}(\mathrm{t})$ is the $\mathrm{RF}$ input signal. $\mathrm{A}, \mathrm{V}_{1}$ are the amplitude from the laser diode (LD) and RF oscillator, respectively $\omega_{0} \mathrm{t} \& \omega_{1} \mathrm{t}$ angular frequency. $\emptyset_{0}(\mathrm{t}) \& \emptyset_{1}(\mathrm{t})$ phase noise ratio.

After optically modulated $x_{1}(\mathrm{t})$ by $x_{1}(\mathrm{t})$ with a MZM, the output signal of the MZM is:

$$
\begin{aligned}
E_{\text {OSSB }}(0, t)=\frac{A \cdot L_{0}}{\sqrt{2}} & \left\{\operatorname { e x p j } \left[\omega_{0} \mathrm{t}+\gamma \pi+\emptyset_{0}(\mathrm{t})\right.\right. \\
& +\alpha \pi \cos \left(\omega_{1} \mathrm{t}+\emptyset_{1}(\mathrm{t})\right] \\
& +\operatorname{expj}\left[\omega_{0} \mathrm{t}+\emptyset_{0}(\mathrm{t})\right. \\
& \left.+\alpha \pi \cos \left(\omega_{1} \mathrm{t}+\emptyset_{1}(\mathrm{t})+\theta\right]\right\}
\end{aligned}
$$

$E_{\text {ODSB }}(0, t)=\frac{A \cdot L_{0}}{\sqrt{2}}\left\{\operatorname{expj}\left[\omega_{0} \mathrm{t}+\pi+\emptyset_{0}(\mathrm{t})+\alpha \pi \cos \left(\omega_{1} \mathrm{t}+\right.\right.\right.$ $\emptyset 1(\mathrm{t})+\exp j \omega 0 \mathrm{t}+\emptyset 0 \mathrm{t}+$ $\alpha \pi \cos (\omega 1 \mathrm{t}+\emptyset 1(\mathrm{t})+\pi$ (1.4)

Where, $x_{1}(\mathrm{t})$ denotes the phase shift version of $x_{1}(\mathrm{t}) . \gamma=$ ( $V_{\mathrm{dc}} / V_{\pi}$ ) and $\propto=V_{1} / \sqrt{2} V_{\pi}$, normalizing dc and ac value, $V_{\pi}$ is 
the switching voltage of the MZM. $L_{0}$ is the insertion loss. And the $\theta$ is the phase shift by the phase shifter. For generating the OSSB scheme $\theta$ and $\gamma$ are set to $\pi / 2$ and $1 / 2$, and the ODSB scheme $\theta$ and $\gamma$ are set to $\pi$ and 1. The OSSB, ODSB and OVSB scheme at the MZM can be modeled as follow:

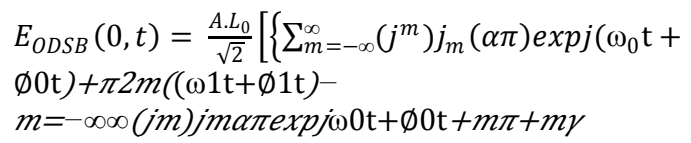

$E_{\text {OSSB }}(0, t)=A L_{0}\left\{J_{0}(\alpha \pi) \operatorname{expj}\left(\omega_{0} \mathrm{t}+\emptyset_{0}\left(\mathrm{t}-\tau_{0}\right)-\emptyset_{1}+\right.\right.$

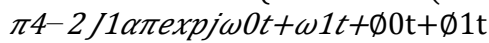

$E_{O D S B}(0, t)=\frac{A L_{0}}{\sqrt{2}}\left\{J_{0}(\alpha \pi) \operatorname{expj}\left(\omega_{0} \mathrm{t}+\emptyset_{0}\left(\mathrm{t}-\tau_{0}\right)-\emptyset_{1}+\right.\right.$

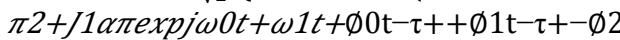

$E_{O S S B}(\mathrm{~L}, \mathrm{t})$

$=\mathrm{A} \cdot \mathrm{L}_{0} \mathrm{~L}_{1} \cdot 10^{\frac{-\alpha_{0} \mathrm{~L}_{2}}{20}} \cdot \mathrm{J}_{0}(\alpha \pi)$

$\times\left\{\exp j\left(\omega_{0} t+\emptyset_{0}(t-\tau 0)-\emptyset_{1}+\frac{\pi}{4}\right)\right.$

$-\frac{\sqrt{2} \mathrm{~J}_{1}(\alpha \pi)}{\mathrm{J}_{0}(\propto \pi)} \operatorname{expj}\left(\omega_{0} t+\omega_{1} t+\emptyset_{0}\left(t-\tau_{+}\right)+\emptyset_{1}\left(t-\tau_{+}\right)\right.$

$\left.\left.-\emptyset_{2}\right)\right\}$

$\mathrm{E}_{\text {OVSB }}(\mathrm{L}, \mathrm{t})=\left[A \cdot \mathrm{L}_{\mathrm{O}} \mathrm{L}_{1} \cdot 10^{\frac{-\alpha_{0} L_{2}}{20}}\right]\left\{\mathrm{PJ}_{0}(\varnothing) \mathrm{e}^{\mathrm{j} \omega_{2} \mathrm{t}}+\right.$

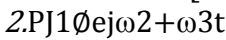

$\mathrm{E}_{\mathrm{ODSB}}(\mathrm{L}, \mathrm{t})=\mathrm{A} \cdot \mathrm{L}_{0} \mathrm{~L}_{1} \cdot 10^{\frac{-\alpha_{0} \mathrm{~L}_{2}}{20}} \cdot \frac{\mathrm{J}_{0}(\alpha \pi)}{\sqrt{2}} \times\left\{\operatorname{expj}\left(\omega_{0} \mathrm{t}+\right.\right.$ $\emptyset 0 \mathrm{t}-\tau 0-\emptyset 1+\pi 2-2$

$\mathrm{J} 1 \alpha \pi \mathrm{J} 0 \propto \pi \operatorname{expj} \omega 0 \mathrm{t}+\omega 1 \mathrm{t}+\emptyset 0 \mathrm{t}-\tau++\emptyset 1 \mathrm{t}-\tau+-\varnothing 2$

Where, $L_{1}$ denotes an additional loss in the optical links, $\alpha_{0}$ is the single mode fiber (SMF) loss, $L_{2}$ is the transmission distance of the SMF, and $\tau_{0}$ and $\tau_{+}$define group delays for a center angular frequency of $\omega_{L D}$ and an upper sideband frequency of $\omega_{0}+\omega_{1} . \emptyset_{1}$ and $\emptyset_{2}$ are phase - shift parameter for specific frequencies due to the fiber chromatic dispersion. Where equation 2 shows the expression of the MZM produce infinite number of sidebands at frequencies $\left(\omega_{2} \pm \omega_{3}\right)$, $\left(\omega_{2} \pm 2 \omega_{3}\right)$ and so on. So taking a first order side band. Where $\omega_{2}$ and $\omega_{3}$ are the frequencies of optical carrier and electrical signal respectively. A and $A_{c}$ is the amplitude and amplitude of the optical carrier respectively. Assuming $\mathrm{q}$ $=A_{c} \cos (c) J_{0}(m), \mathrm{m}=\frac{\pi|M(t)|}{V_{\pi}}$ and $c=\frac{\pi V_{b}}{V_{\pi}}, \quad V_{\pi}$ is the half wave voltage of modulator and $V_{b}$ is the applied dc bias voltage to the modulator, $\mathrm{M}(\mathrm{t})=V_{\text {in }} \cos \left(\omega_{3} t\right)$ is the modulated electrical signal. $\varnothing$ is the PM index in radian By using a square -law model, the photocurrent (PD), $i_{p d}(t)$ calculated equation (1.5), (1.6), (1.7)

$$
i_{p d}(t) \cong R|E(L, t)|^{2}
$$

Where $\mathrm{R}$ denotes the responstivity of the PD and $|.|^{2}$ is the square law detection.

$$
\begin{aligned}
& i_{p d O S S B}(t)=\mathrm{R} \cdot A_{1}^{2}\left[\mathrm{~B}+2 \alpha_{1} \cos \right. \\
& \tau 0+\emptyset 1 t-\tau+-\varnothing 2+\emptyset 1
\end{aligned}
$$

Where, for OSSB scheme

$$
\begin{gathered}
A_{1}=A \cdot L_{0} L_{1} \cdot 10^{\frac{-\alpha_{0} \mathrm{~L}_{2}}{20}} \cdot J_{0}(\alpha \pi) \\
\propto_{1}=\frac{\sqrt{2} J_{1}(\alpha \pi)}{J_{0}(\propto \pi)} \\
\mathrm{B}=1+\alpha_{1}^{2} \\
i_{p d O V S B}(t)=\mathrm{R} \cdot A_{2}^{2}\left[B_{1}+2 \alpha_{2} \cos \left(\omega_{3}+\emptyset_{0}\left(t-\tau_{+}\right)-\emptyset_{0}(t-\right.\right. \\
\tau 0+\varnothing 1 t-\tau+-\varnothing 2+\varnothing 1)]
\end{gathered}
$$

Where, OVSB scheme

$$
\begin{gathered}
A_{2=} A \cdot L_{0} L_{1} \cdot 10^{\frac{-\alpha_{0} \mathrm{~L}_{2}}{20}} \cdot J_{0}(\alpha \pi) \cdot P \cdot J_{0}(\varnothing) \\
\alpha_{2}=\frac{2 J_{1}(\alpha \pi)}{J_{0}(\propto \pi)} \\
B_{1}=1+\alpha_{2}^{2} \\
\mathrm{i}_{\text {pdODSB }}(\mathrm{t})=\mathrm{R} \cdot \mathrm{A}_{3}^{2}\left[\mathrm{~B}_{2}+2 \alpha_{3} \cos \left(\omega_{1}+\emptyset_{0}\left(\mathrm{t}-\tau_{+}\right)-\emptyset_{0}(\mathrm{t}-\right.\right. \\
\tau 0+\emptyset 1 \mathrm{t}-\tau+-\emptyset 2+\emptyset 1)]
\end{gathered}
$$

Where, for the ODSB scheme,

$$
\begin{gathered}
A_{3}=A \cdot L_{0} L_{1} \cdot 10 \frac{-\alpha_{0} L_{2}}{20} \cdot \frac{J_{0}(\alpha \pi)}{\sqrt{2}} \\
\propto_{3}=\frac{J_{1}(\alpha \pi)}{J_{0}(\propto \pi)} \\
B_{2}=1+\alpha_{3}^{2}
\end{gathered}
$$

The autocorrelation function $\mathrm{R}_{\mathrm{I}}(\tau)$ is obtained as: $\mathrm{R}_{\mathrm{I}}(\tau)=<\mathrm{i}_{\mathrm{p}}(\mathrm{t}) \cdot \mathrm{i}_{\mathrm{p}}((\mathrm{t}+\tau)>$

$$
\begin{aligned}
& \frac{\mathrm{R}_{\text {OSSB }}(\tau)}{\mathrm{R}^{2} \mathrm{~A}_{1}^{4}} \\
& =B^{2} \\
& +\left\{\begin{array}{rr}
2 \alpha_{1}^{2} \cos \left(\omega_{1} \tau\right) \mathrm{e}^{-2 \gamma_{\mathrm{t}}|\tau|}, & |\tau| \leq \tau_{1} \\
2 \alpha_{1}^{2} \cos \left(\omega_{1} \tau\right) \times \mathrm{e}^{-2 \gamma_{0} \tau_{1}-\gamma_{1|\tau|}}, & |\tau|>\tau_{1} \tau_{1}
\end{array}\right\}
\end{aligned}
$$

$$
\begin{aligned}
& \frac{\mathrm{R}_{\mathrm{OVSB}}(\tau)}{\mathrm{R}^{2} \mathrm{~A}_{2}^{4}} \\
& =B_{1}^{2} \\
& +\left\{\begin{array}{cc}
2 \alpha_{2}^{2} \cos \left(\omega_{1} \tau\right) e^{-2 \gamma_{t}|\tau|}, & |\tau| \leq \tau_{1} \\
2 \alpha_{2}^{2} \cos \left(\omega_{1} \tau\right) \times e^{-2 \gamma_{0} \tau_{1}-\gamma_{1|\tau|}}, & |\tau|>\tau_{1}
\end{array}\right\}
\end{aligned}
$$


$\frac{\mathrm{R}_{\mathrm{ODSB}}(\tau)}{\mathrm{R}^{2} \mathrm{~A}_{3}^{4}}$

$=B_{2}^{2}$

$+\left\{\begin{array}{cc}2 \alpha_{3}^{2} \cos \left(\omega_{1} \tau\right) e^{-2 \gamma_{t}|\tau|}, & |\tau| \leq \tau_{1} \\ 2 \alpha_{3}^{2} \cos \left(\omega_{1} \tau\right) \times e^{-2 \gamma_{0} \tau_{1}-\gamma_{1|\tau|},} & |\tau|>\tau_{1}\end{array}\right\}$

Where where $\Delta V_{0}$ and $\Delta V_{1}$ are the linewidths for the laser and the RF oscillator, respectively, $2 \gamma_{0}\left(=2 \pi \Delta V_{0}\right)$ and $2 \gamma_{1} \quad(=$ $\left.2 \pi \Delta V_{0}\right)$ define the angular full-linewidth at halfmaximum (FWHM) of the Lorentzian shape for the laser and the RF oscillator, respectively, and $2 \gamma_{t}$ is related to the total line width. Note that the $2 \gamma_{t}$ is given not as $2 \pi \Delta V_{0}+2 \pi \Delta V_{1}$ but $\left.2 \pi \Delta V_{0}+\pi \Delta V_{1}, \tau_{1(=} \tau_{+}-\tau_{0}\right)$ is the differential delay due to the fiber chromatic dispersion and is dependent on the wavelength $\lambda$, the carrier frequency $f_{R F}$, the fiber chromatic dispersion $\mathrm{D}$, and the optical transmission distance $L_{2}$

$$
\tau_{1}=D \cdot L_{2} \cdot \lambda^{2} \frac{f_{1}}{C}
$$

Where $\mathrm{c}$ is the light velocity. When $\gamma_{1}$ is equal to 0 . The PSD function of the photocurrent is given by the Fourier transform of (1.11) (1.12) and(1.13). The shot noise term at the PD is omitted here since the noise power can be evaluated by the product of bandwidth and noise density level. The PSD function $S_{I}(\mathrm{f})$ can be written as:

$$
S_{I}(f)=F\left\langle R_{I}(\tau)\right\rangle
$$

$$
\begin{aligned}
& \frac{S_{\text {IOSSB }}(f)}{R^{2} A_{1}^{4}}= \\
& B^{2} \partial(f)+\alpha_{1}^{2}\left\{\int_{-\tau_{1}}^{0}\left(e^{\tau\left(j \omega_{d}+2 \gamma_{t}\right)}+e^{\tau\left(-j \omega_{d}+2 \gamma_{t}\right)}\right) e^{\tau(-j \omega)} d \tau+\right. \\
& \left.\int_{0}^{\tau_{1}}\left(e^{\tau\left(j \omega_{d}-2 \gamma_{t}\right)}+e^{\tau\left(-j \omega_{d}-2 \gamma_{t}\right)}\right) e^{\tau(-j \omega)} d \tau+\right\}+ \\
& e^{-2 \gamma_{0}|\tau|}\left\{\int_{-\tau_{1}}^{\infty}\left(e^{\tau\left(j \omega_{d}-2 \gamma_{1}\right)}+e^{\tau\left(-j \omega_{d}-2 \gamma_{1}\right)}\right) e^{\tau(-j \omega)} d \tau\right\}
\end{aligned}
$$

$\frac{\mathrm{S}_{\mathrm{IOVSB}}(\mathrm{f})}{\mathrm{R}^{2} \mathrm{~A}_{2}^{4}}=$

$B_{1}^{2} \partial(f)+\alpha_{2}^{2}\left\{\int_{-\tau_{1}}^{0}\left(e^{\tau\left(j \omega_{d}+2 \gamma_{t}\right)}+e^{\tau\left(-j \omega_{d}+2 \gamma_{t}\right)}\right) e^{\tau(-j \omega)} d \tau+\right.$ $0 \tau 1 \mathrm{e} \tau \mathrm{j} \omega \mathrm{d}-2 \gamma \mathrm{t}+\mathrm{e} \tau-\mathrm{j} \omega \mathrm{d}-2 \gamma \mathrm{te} \tau(-\mathrm{j} \omega) \mathrm{d} \tau++\mathrm{e}-2 \gamma 0 \tau-\tau 1 \infty \mathrm{e} \tau \mathrm{j} \omega \mathrm{d}-2 \gamma$ $1+\mathrm{e} \tau-\mathrm{j} \omega \mathrm{d}-2 \gamma 1 \mathrm{e} \tau-\mathrm{j} \omega \mathrm{d} \tau$

\section{$\frac{\mathrm{S}_{\mathrm{IODSB}}(\mathrm{f})}{\mathrm{R}^{2} \mathrm{~A}_{3}^{4}}=$}

$B_{2}^{2} \partial(f)+\alpha_{3}^{2}\left\{\int_{-\tau_{1}}^{0}\left(e^{\tau\left(j \omega_{d}+2 \gamma_{t}\right)}+e^{\tau\left(-j \omega_{d}+2 \gamma_{t}\right)}\right) e^{\tau(-j \omega)} d \tau+\right.$

$0 \tau 1 \mathrm{e} \tau \mathrm{j} \omega \mathrm{d}-2 \gamma \mathrm{t}+\mathrm{e} \tau-\mathrm{j} \omega \mathrm{d}-2 \gamma \mathrm{te} \tau(-\mathrm{j} \omega) \mathrm{d} \tau++\mathrm{e}-2 \gamma 0 \tau-\tau 1 \infty \mathrm{e} \tau \omega \mathrm{d}-2 \gamma$

$1+\mathrm{e} \tau-\mathrm{j} \omega \mathrm{d}-2 \gamma 1 \mathrm{e} \tau-\mathrm{j} \omega \mathrm{d} \tau$

(1.17)

The received RF carrier power is obtained as

$$
\begin{array}{r}
\mathrm{P}_{\mathrm{REC}}=2 \int_{\mathrm{f}_{1-\frac{\mathrm{B}_{1}}{2}}}^{{ }_{11+\frac{\mathrm{B}_{1}}{2}}^{\mathrm{f}}} \mathrm{S}_{\mathrm{I}}(\mathrm{f}) \mathrm{df} \\
P_{\text {RECOSSB }}=\frac{4 \mathrm{R}^{2} \mathrm{~A}_{1}^{4} \alpha_{1}^{2}}{\pi} e^{-2 \gamma_{t} \tau_{1} \cdot \tan ^{-1}\left(\frac{\pi B_{1}}{\gamma_{1}}\right)} \\
\mathrm{P}_{\mathrm{RECOVSB}}=\frac{4 \mathrm{R}^{2} \mathrm{~A}_{2}^{4} \alpha_{2}^{2}}{\pi} e^{-2 \gamma_{t} \tau_{1} \cdot \tan ^{-1}\left(\frac{\pi B_{1}}{\gamma_{1}}\right)}
\end{array}
$$

$$
P_{R E C O D S B}=\frac{4 R^{2} A_{3}^{4} \alpha_{3}^{2}}{\pi} e^{-2 \gamma_{t} \tau_{1} \cdot \tan ^{-1}\left(\frac{\pi B_{1}}{\gamma_{1}}\right)}
$$

For evaluating the total RF power excluding dc power, utilizing equ (1.18) (1.19) (1.20) and putting $\tau_{1}=0$. Total power is obtained as :

$$
\begin{aligned}
& P_{\text {IOSSB }}=2 R^{2} A_{1}^{4} \alpha_{1}^{2} \\
& P_{\text {IOVSB }}=2 R^{2} A_{2}^{4} \alpha_{2}^{2} \\
& P_{\text {IODSB }}=2 R^{2} A_{3}^{4} \alpha_{3}^{2}
\end{aligned}
$$

The percentage of received power which considers the effect of the filter bandwidth $\left(B_{R F}\right)$ at an electrical receiver, is found as the ratio between the total carrier power ant the required power as:

$\mathrm{P}=\frac{P_{R E C}}{P_{I}}$ for $2 \gamma_{t} \tau_{t} \ll 1$ and $\gamma_{t} \ll \gamma_{1}$

$\cong \frac{2}{\pi} e^{-2 \gamma_{t} \tau_{t}} \cdot \tan ^{-1}\left(\frac{\pi B_{1}}{\gamma_{1}}\right)$

The required bandwidth for the $\mathrm{P}$ ratio is obtained as:

$$
B_{1}=\frac{\gamma_{1}}{\pi} \tan \left(\frac{\pi}{2} e^{2 \gamma_{t} \tau_{t}} p\right)
$$

The required bandwidth increases as we need more received signal power. Note that the required bandwidth for a specific received carrier power is dominantly dependent on the phase noise from the RF oscillator rather than that from the laser for $2 \gamma_{t} \tau_{t} \ll 1$ and $\gamma_{t \ll} \gamma_{1}$ However, when $2 \gamma_{t} \tau_{t}$ is not enough to be ignored and $e^{\gamma_{t} \tau_{t}} p$ apapproaches $1, B_{1}$ will be infinite. In this paper, we focus on the range of $e^{\gamma_{t} \tau_{t}} p<1$

the SNR penalty induced by the differential delay from the fiber chromatic dispersion and the line widths from the laser and the RF oscillator is found as:

$$
\mathrm{SNR}=\frac{\text { Carrier power }}{\text { noise } \text { power }}
$$

$$
\begin{gathered}
S N R=\frac{P_{I}}{2 B_{R F} \cdot \frac{N_{O}}{2}} \\
S N R_{O S S B}=\frac{2 R^{2} A_{I}^{4} \alpha_{I}^{2} \mathrm{p}}{N_{0} \frac{\gamma_{I}}{\pi} \tan \left(\frac{\pi}{2} e^{2 \gamma_{t} \tau_{t}} p\right)} \\
S N R_{O V S B}=\frac{2 R^{2} A_{2}^{4} \alpha_{2}^{2} \mathrm{p}}{N_{0} \frac{\gamma_{I}}{\pi} \tan \left(\frac{\pi}{2} e^{2 \gamma_{t} \tau_{t}} p\right)} \\
S N R_{O D S B}=\frac{2 R^{2} A_{3}^{4} \alpha_{3}^{2} \mathrm{p}}{N_{0} \frac{\gamma_{I}}{\pi} \tan \left(\frac{\pi}{2} e^{2 \gamma_{t} \tau_{t}} p\right)} \\
S N R_{O S S B}=\frac{1.129 * 10^{-4} \mathrm{p}}{N_{0} \frac{\gamma_{I}}{\pi} \tan \left(\frac{\pi}{2} e^{2 \gamma_{t} \tau_{t}} p\right)} \\
S N R_{O V S B}=\frac{3.46 * 10^{-5} \mathrm{p}}{N_{O} \frac{\gamma_{I}}{\pi} \tan \left(\frac{\pi}{2} e^{2 \gamma_{t} \tau_{t}} p\right)}
\end{gathered}
$$


$\operatorname{SNR}_{O S S B}=\frac{1.41 * 10^{-5} \mathrm{p}}{N_{0} \frac{\gamma_{1}}{\pi} \tan \left(\frac{\pi}{2} e^{2 \gamma_{t} \tau_{t}} p\right)}$

Thus it is observed that the SNR is independent on the percentage of received power which is function of required bandwidth phase noise from RF oscillator \& laser line width, length of fiber and RF signal power.

\section{PRINCIPLE MODEL DIAGRAM}

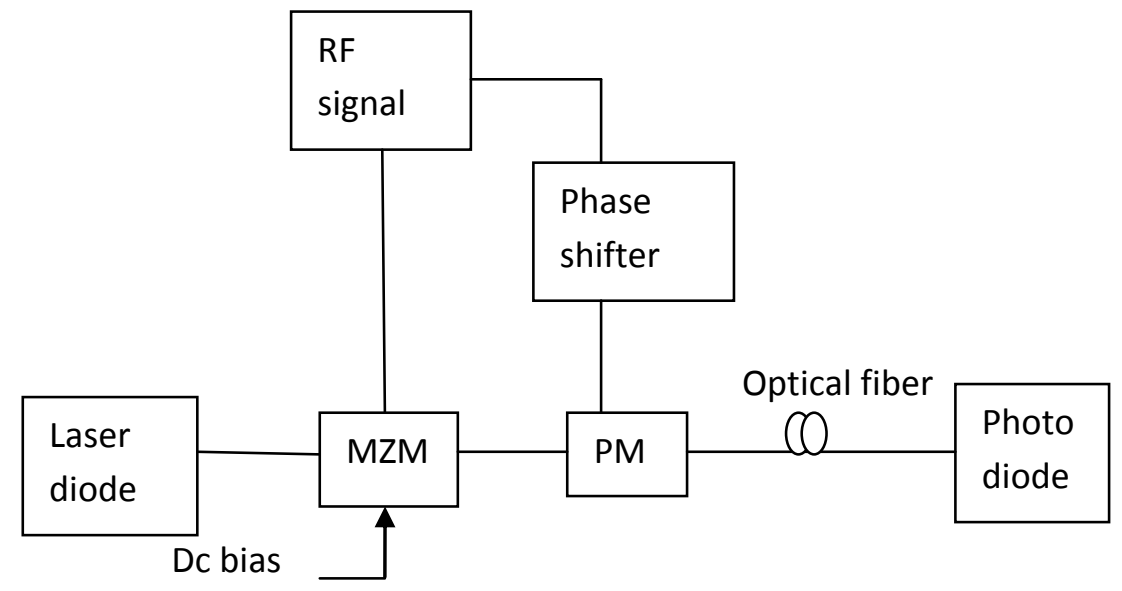

Fig 1.1: optical spectrum of optical single sideband modulation, optical double sideband, optical vestigial sideband modulation scheme

\section{RESULT AND DISCUSSION}

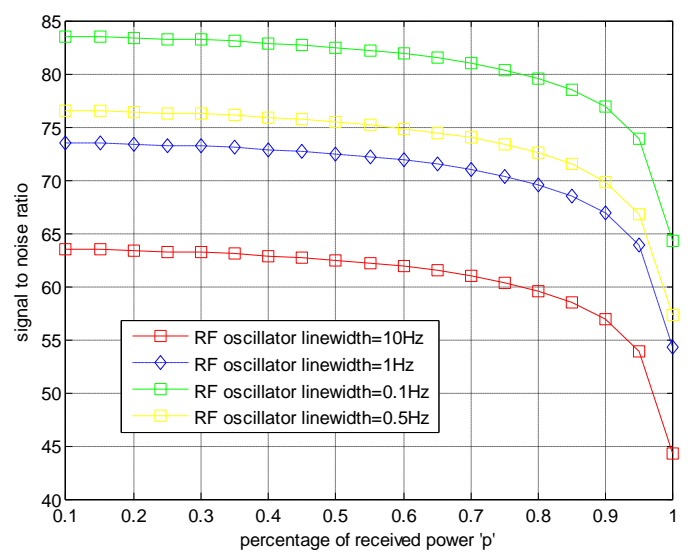

Fig 1.2 signal to noise ratio in terms of percentage of received power different value on $R F$ oscillator line width modulated by OSSB scheme

SNR is sketched in fig 1.2 the line width of RF oscillator has been swept from $0.5 \mathrm{~Hz}$ to $10 \mathrm{~Hz}$. The variation of signal to noise ratio w.r.t to percentage of received power. The value of percentage of received power is varied from 0.1 to 0.9 . the signal to noise ratio value for OSSB external modulation scheme are observed $63.48 \mathrm{dBm}, 73.48 \mathrm{dBm}, 83.48 \mathrm{dBm}$ and $76.495 \mathrm{dBm}$ at 0.1 respectively with RF oscillator line width $10 \mathrm{~Hz}, 1 \mathrm{~Hz}, 0.1 \mathrm{~Hz}$ and $0.5 \mathrm{~Hz}$. The value of percentage of received power is varied from 0.1 to 0.9 . the signal to noise ratio value for OSSB external modulation scheme are observed $62.45 \mathrm{dBm}, 72.45 \mathrm{dBm}, 82.45 \mathrm{dBm}$ and $75.46 \mathrm{dBm}$ at 0.5 respectively with RF oscillator line width $10 \mathrm{~Hz}$,

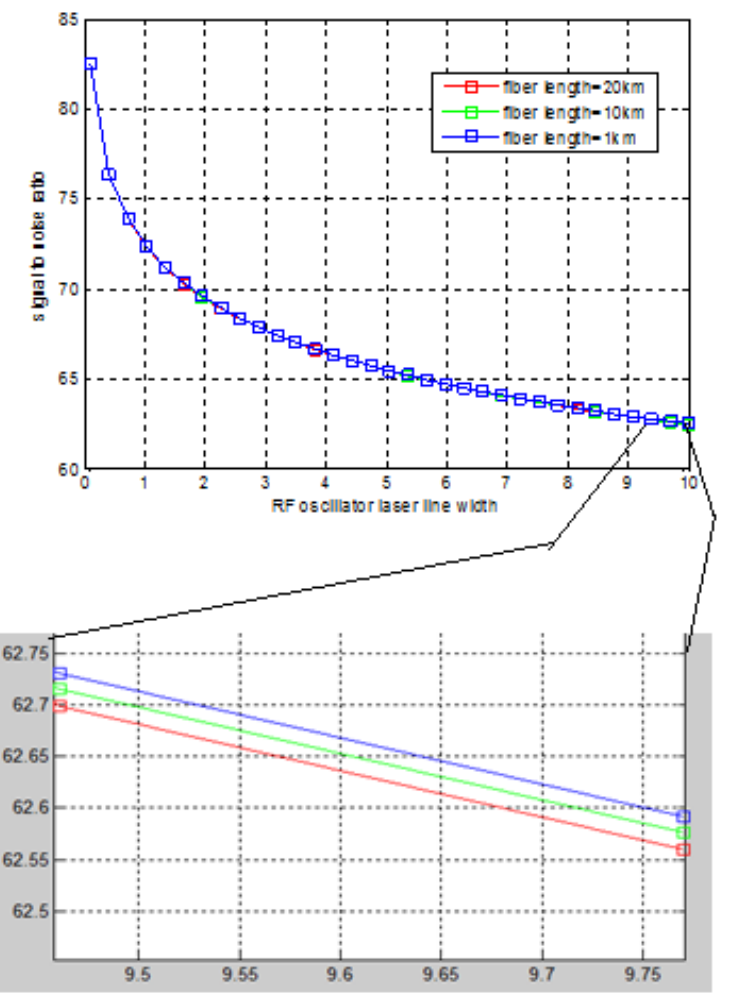

Fig 1.3 signal to noise ratio in terms of RF oscillator line width different value on fiber length modulated by OSSB scheme

$1 \mathrm{~Hz}, 0.1 \mathrm{~Hz}$ and $0.5 \mathrm{~Hz}$. The value of percentage of received power is varied from 0.1 to 0.9 . the signal to noise ratio value for OSSB external modulation scheme are observed $53.82 \mathrm{dBm}, 64.19 \mathrm{dBm}, 73.82 \mathrm{dBm}$ and $66.83 \mathrm{dBm}$ at 0.9 
respectively with RF oscillator line width $10 \mathrm{~Hz}, 1 \mathrm{~Hz}, 0.1 \mathrm{~Hz}$ and $0.5 \mathrm{~Hz}$.

SNR is sketched in fig 1.3 the fiber length has been swept from $20 \mathrm{~km}$ to $1 \mathrm{~km}$. The variation of signal to noise ratio w.r.t to RF oscillator laser line width. The value of RF oscillator laser line width is varied from $0.1 \mathrm{~Hz}$ to $10 \mathrm{~Hz}$. the signal to noise ratio value for OSSB external modulation scheme are observed $83.45 \mathrm{dBm}, 83.47 \mathrm{dBm}, 82.49 \mathrm{dBm}$ and $83.5 \mathrm{dBm}$ at $0.1 \mathrm{~Hz}$ respectively with fiber length $20 \mathrm{~km}, 10 \mathrm{~km}$ and $1 \mathrm{~km}$.the signal to noise ratio value for OSSB external modulation scheme are observed $62.46 \mathrm{dBm}, 62.48 \mathrm{dBm}$ and $62.49 \mathrm{dBm}$ at $10 \mathrm{~Hz}$ respectively with fiber length $20 \mathrm{~km}, 10 \mathrm{~km}$ and $1 \mathrm{~km}$.

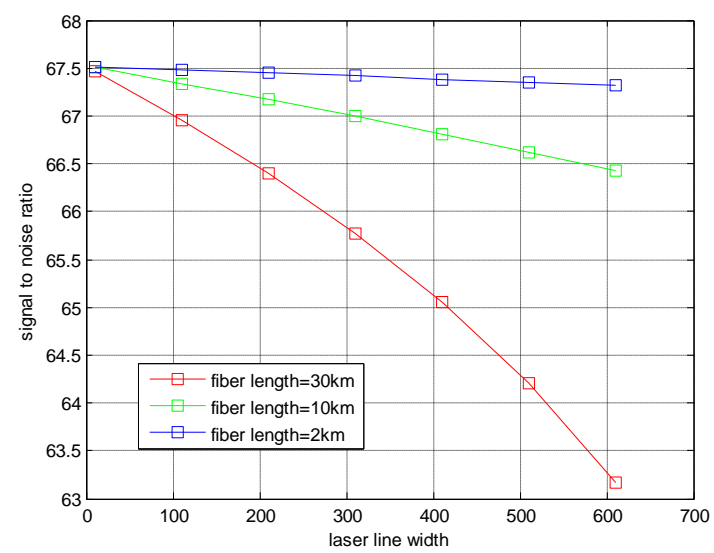

Fig 1.4 signal to noise ratio in terms of laser line width different value on laser length of fiber modulated by OSSB scheme

SNR is sketched in fig 1.4 the fiber length has been swept from $30 \mathrm{~km}$ to $2 \mathrm{~km}$. The variation of signal to noise ratio w.r.t to laser line width. The value of laser line width is varied from $10 \mathrm{MHz}$ to $624 \mathrm{MHz}$. the signal to noise ratio value for OSSB external modulation scheme are observed $67.5 \mathrm{dBm}, 67.5 \mathrm{dBm}$ and $67.5 \mathrm{dBm}$ at $10 \mathrm{MHz}$ respectively with fiber length $30 \mathrm{~km}$, $10 \mathrm{~km}$ and $2 \mathrm{~km}$.

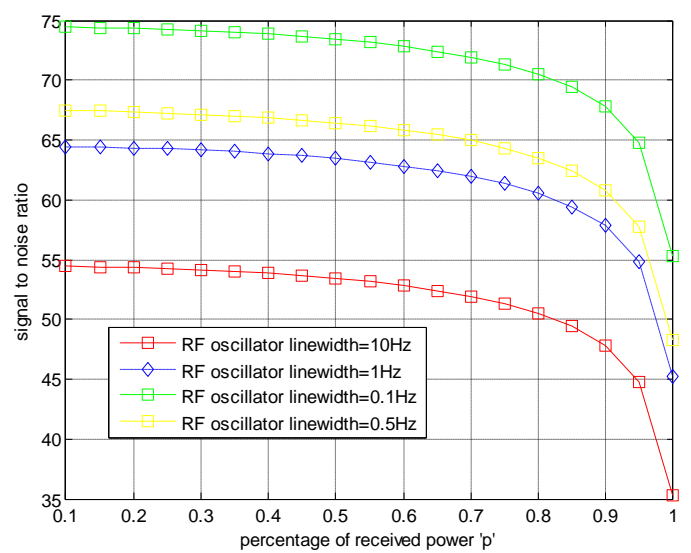

Fig 1.5 signal to noise ratio in terms of percentage of received power different value on $R F$ oscillator line width modulated by ODSB scheme

The signal to noise ratio value for OSSB external modulation scheme are observed $67 \mathrm{dBm}, 67.5 \mathrm{~dB}$ and $67.4 . \mathrm{dBm}$ at $10 \mathrm{MHz}$ respectively with fiber length $30 \mathrm{~km}, 10 \mathrm{~km}$ and $2 \mathrm{~km}$.the signal to noise ratio value for OSSB external modulation scheme are observed $63.2 \mathrm{dBm}$ and $67.4 \mathrm{dBm}$ and $66.49 \mathrm{dBm}$ at $624 \mathrm{MHz}$ respectively with fiber length $30 \mathrm{~km}$, $10 \mathrm{~km}$ and $2 \mathrm{~km}$.

SNR is sketched in fig 1.5 the line width of RF oscillator has been swept from $0.5 \mathrm{~Hz}$ to $10 \mathrm{~Hz}$. The variation of signal to noise ratio w.r.t to percentage of received power. The value of percentage of received power is varied from 0.1 to 0.9 . the signal to noise ratio value for ODSB external modulation scheme are observed $54.49 \mathrm{dBm}, 64.44 \mathrm{dBm}, 74.44 \mathrm{dBm}$ and $67.46 \mathrm{dBm}$ at 0.1 respectively with $\mathrm{RF}$ oscillator line width $10 \mathrm{~Hz}, 1 \mathrm{~Hz}, 0.1 \mathrm{~Hz}$ and $0.5 \mathrm{~Hz}$. The value of percentage of received power is varied from 0.1 to 0.9 . the signal to noise ratio value for ODSB external modulation scheme are observed $53.42 \mathrm{dBm}, 63.42 \mathrm{dBm}, 73.42 \mathrm{dBm}$ and $66.43 \mathrm{dBm}$ at 0.5 respectively with $\mathrm{RF}$ oscillator line width $10 \mathrm{~Hz}$, $1 \mathrm{~Hz}, 0.1 \mathrm{~Hz}$ and $0.5 \mathrm{~Hz}$. The value of percentage of received power is varied from 0.1 to 0.9 . the signal to noise ratio value for ODSB external modulation scheme are observed $44.78 \mathrm{dBm}, 54.78 \mathrm{dBm}, 64.78 \mathrm{dBm}$ and $57.79 \mathrm{dBm}$ at 0.9 respectively with $\mathrm{RF}$ oscillator line width $10 \mathrm{~Hz}, 1 \mathrm{~Hz}, 0.1 \mathrm{~Hz}$ and $0.5 \mathrm{~Hz}$.

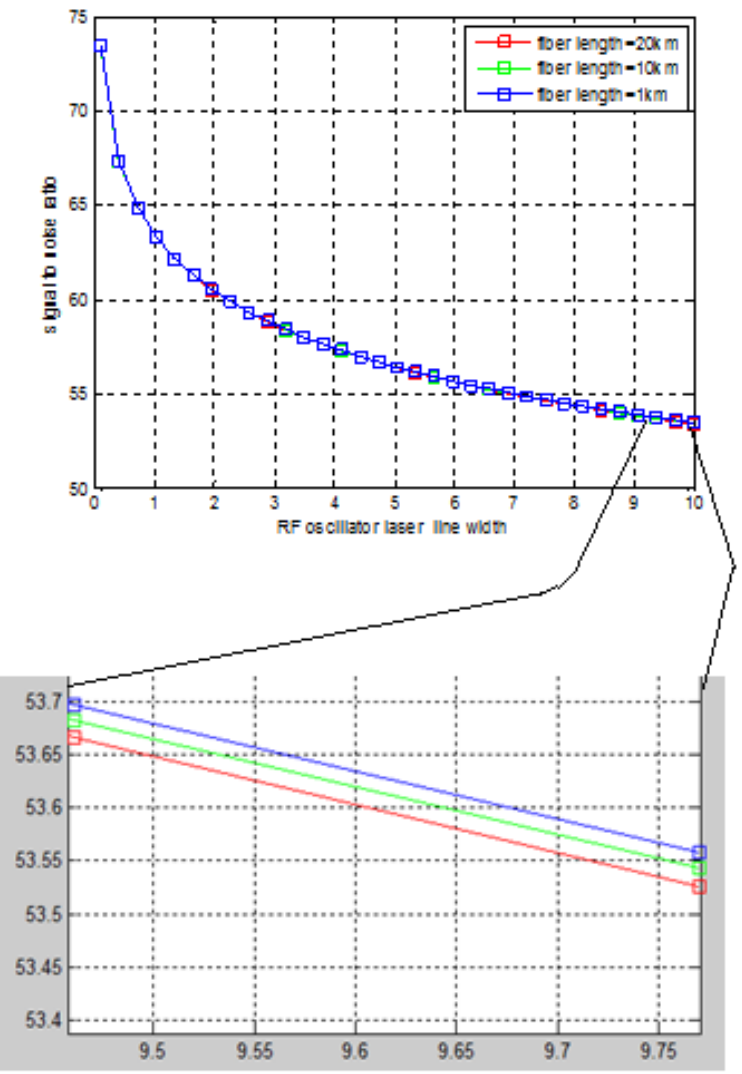

Fig 1.6 RF signal to noise ratio in terms of oscillator line width different value on length of fiber width modulated by ODSB scheme

SNR is sketched in fig1.6. The fiber length has been swept from $20 \mathrm{~km}$ to $1 \mathrm{~km}$. The variation of signal to noise ratio w.r.t to RF oscillator laser line width. The value of RF oscillator laser line width is varied from $0.1 \mathrm{~Hz}$ to $10 \mathrm{~Hz}$. the signal to noise ratio value for ODSB external modulation scheme are observed $73.42 \mathrm{dBm}, 73.41 \mathrm{dBm}$ and $73.45 \mathrm{dBm}$ at $0.1 \mathrm{~Hz}$ respectively with fiber length $20 \mathrm{~km}, 10 \mathrm{~km}$ and $1 \mathrm{~km}$.the signal to noise ratio value for ODSB external modulation scheme are 
observed $53.43 \mathrm{dBm}, 53.44 \mathrm{dBm}$ and $53.46 \mathrm{dBm}$ at $10 \mathrm{~Hz}$ respectively with fiber length $20 \mathrm{~km}, 10 \mathrm{~km}$ and $1 \mathrm{~km}$.

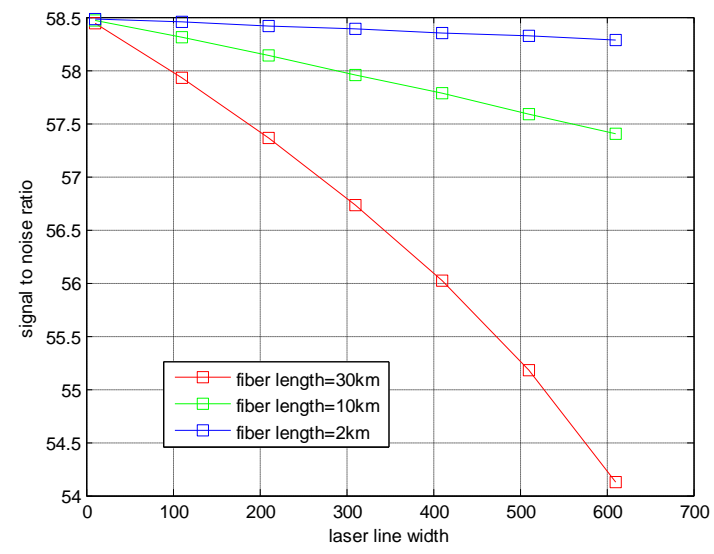

Fig 1.7 signal to noise ratio in terms of laser line width different value on fiber length of fiber modulated by ODSB scheme

SNR is sketched in fig 1.7 the fiber length has been swept from $30 \mathrm{~km}$ to $2 \mathrm{~km}$. The variation of signal to noise ratio w.r.t to laser line width. The value of laser line width is varied from $10 \mathrm{MHz}$ to $624 \mathrm{MHz}$. the signal to noise ratio value for OSSB external modulation scheme are observed $58.5 \mathrm{dBm}, 58.5 \mathrm{dBm}$ and $58.5 \mathrm{dBm}$ at $10 \mathrm{MHz}$ respectively with fiber length $30 \mathrm{~km}$, $10 \mathrm{~km}$ and $2 \mathrm{~km}$. The the signal to noise ratio value for OSSB external modulation scheme are observed $58 \mathrm{dBm}, 58.49 \mathrm{~dB}$ and $58.4 . \mathrm{dBm}$ at $10 \mathrm{MHz}$ respectively with fiber length $30 \mathrm{~km}$, $10 \mathrm{~km}$ and $2 \mathrm{~km}$.the signal to noise ratio value for OSSB external modulation scheme are observed $54.2 \mathrm{dBm}$ and $57.4 \mathrm{dBm}$ and $58.35 \mathrm{~Hz}$ at $624 \mathrm{MHz}$ respectively with fiber length $30 \mathrm{~km}, 10 \mathrm{~km}$ and $2 \mathrm{~km}$.

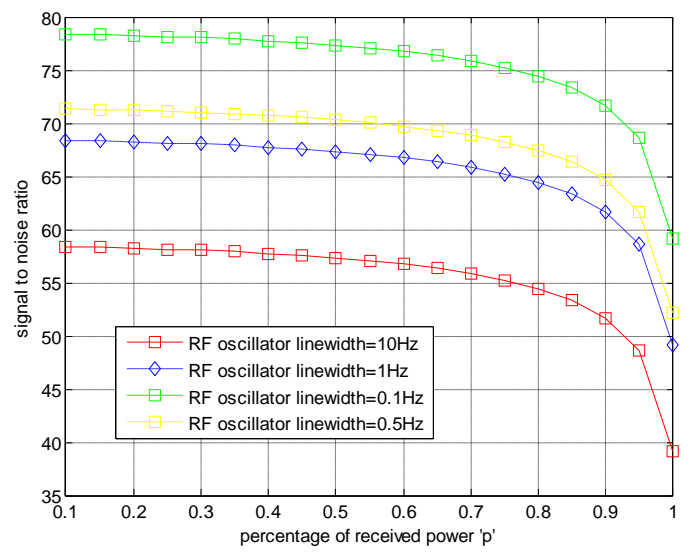

Fig 1.8 signal to noise ratio in terms of percentage of received power different value on oscillator laser line width modulated by OVSB scheme

SNR is sketched in fig 1.8. the line width of RF oscillator has been swept from $0.5 \mathrm{~Hz}$ to $10 \mathrm{~Hz}$. The variation of signal to noise ratio w.r.t to percentage of received power. The value of percentage of received power is varied from 0.1 to 0.9 . the signal to noise ratio value for OVSB external modulation scheme are observed $58.34 \mathrm{dBm}, 68.34 \mathrm{dBm}, 78.34 \mathrm{dBm}$ and $71.35 \mathrm{dBm}$ at 0.1 respectively with $\mathrm{RF}$ oscillator line width $10 \mathrm{~Hz}, 1 \mathrm{~Hz}, 0.1 \mathrm{~Hz}$ and $0.5 \mathrm{~Hz}$. The value of percentage of received power is varied from 0.1 to 0.9 . the signal to noise ratio value for OVSB external modulation scheme are observed $57.03 \mathrm{dBm}, 67.31 \mathrm{dBm}, 77.31 \mathrm{dBm}$ and $70.30 \mathrm{dBm}$ at 0.1 respectively with $\mathrm{RF}$ oscillator line width $10 \mathrm{~Hz}$, $1 \mathrm{~Hz}, 0.1 \mathrm{~Hz}$ and0.5 Hz. The value of percentage of received power is varied from 0.1 to 0.9 . the signal to noise ratio value for OVSB external modulation scheme are observed $48.68 \mathrm{dBm}, 58.68 \mathrm{dBm}, 68.68 \mathrm{dBm}$ and $61.69 \mathrm{dBm}$ at 0.1 respectively with $\mathrm{RF}$ oscillator line width $10 \mathrm{~Hz}, 1 \mathrm{~Hz}, 0.1 \mathrm{~Hz}$ and $0.5 \mathrm{~Hz}$.

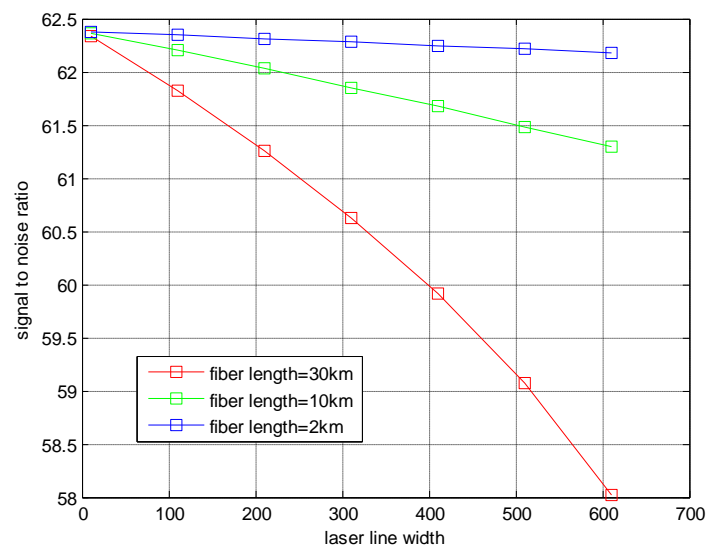

Fig 1.9 signal to noise ratio in terms of laser line width different value on fiber length of fiber modulated by OVSB scheme

SNR is sketched in fig 1.9 the fiber length has been swept from $30 \mathrm{~km}$ to $2 \mathrm{~km}$. The variation of signal to noise ratio w.r.t to laser line width. The value of laser line width is varied from $10 \mathrm{MHz}$ to $624 \mathrm{MHz}$. the signal to noise ratio value for OSSB external modulation scheme are observed $62.33 \mathrm{dBm}$, $62.36 \mathrm{dBm}$ and $62.37 \mathrm{dBm}$ at $10 \mathrm{MHz}$ respectively with fiber length $30 \mathrm{~km}, 10 \mathrm{~km}$ and $2 \mathrm{~km}$.the signal to noise ratio value for OSSB external modulation scheme are observed $58.02 \mathrm{dBm}$ and $61.29 \mathrm{dBm}$ and $62.17 \mathrm{dBm}$ at $624 \mathrm{MHz}$ respectively with fiber length $30 \mathrm{~km}, 10 \mathrm{~km}$ and $2 \mathrm{~km}$. 


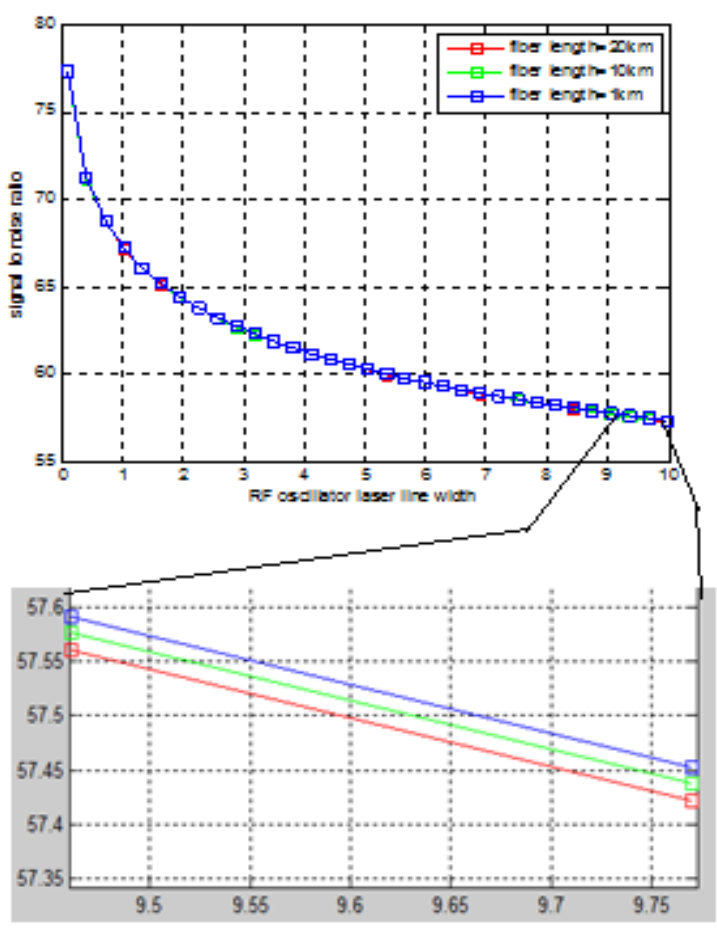

Fig 1.10 signal to noise ratio in terms of $\mathrm{RF}$ oscillator line width different value on fiber length modulated by OVSB scheme

SNR is sketched in fig 1.10 the fiber length has been swept from $20 \mathrm{~km}$ to $1 \mathrm{~km}$. The variation of signal to noise ratio w.r.t to $\mathrm{RF}$ oscillator laser line width. The value of RF oscillator laser line width is varied from $0.1 \mathrm{~Hz}$ to $10 \mathrm{~Hz}$. the signal to noise ratio value for OVSB external modulation scheme are observed $77.31 \mathrm{dBm}, 77.33 \mathrm{dBm}$ and $77.35 \mathrm{dBm}$ at $0.1 \mathrm{~Hz}$ respectively with fiber length $20 \mathrm{~km}, 10 \mathrm{~km}$ and $1 \mathrm{~km}$. the signal to noise ratio value for OVSB external modulation scheme are observed $57.32 \mathrm{dBm}, 57.34 \mathrm{dBm}$ and $57.35 \mathrm{dBm}$ at $10 \mathrm{~Hz}$ respectively with fiber length $20 \mathrm{~km}, 10 \mathrm{~km}$ and $1 \mathrm{~km}$.

\section{CONCLUSION}

In this paper, the mathematical analysis is derived for external modulation scheme such as OSSB, ODSB and OVSB based on MZM and PM. The RoF system performance parameter, SNR is evaluated in terms percentage of received power, RF oscillator laser line width, laser line width. It is concluded that OVSB scheme is utilized in designing RoF system and prove to be cost effective in compare with OSSB and more performance efficient than ODSB scheme. Finally, It is predicted that the RoF system will become backbone of next generation mobile communication system.

\section{REFERENCES}

[1] Cho, T., and Yun, C., "Analysis of CNR penlty of radio over fiber system including the effect of phase noise from laser RF oscillator", Journal of Lightwave Technology, vol.23,No.12 December (2005).

[2] Parajuli, H., and Udvary,E "A vestigial sideband modulation scheme in radio- over -fiber system using electro-optic modulators",IEEE.

[3] Sharma,V., Singh, A., and .Sharma, A.K.," simulative investigation on the impact of laser spectral width in single- tone radio over fiber transmission system using optical single side band technique," optics and laser in engineering (2009).

[4] Barry.J.R. and Lee.A.E. 'Performance of coherent optical receivers”, proc. inst. Elect .eng., vol. 78, no. 8.(1990).

[5] Pan. S.L. and Xue, M., "Optical vector network analyzer based on optical singlesideband modulation,"presented at the 12th Int. Conf. Optical Communications and Networks, Chengdu, China, (2013).

[6] Kumar, P., Sharma, S.K., and Singla, S., "Performance analysis of an OSSB RoF link using $90^{\circ}$ and $120^{\circ}$ hybrid coupler", Optics Communication, Elsevier Journal, (2015). 